\title{
Adoption of a Personal Health Record in the Digital Age: Cross-Sectional Study
}

Consuela Cheriece Yousef ${ }^{1,2,3}$, PharmD, MPH, BCPS; Abin Thomas ${ }^{2,4,5}$, MSc; Ahmed O Alenazi ${ }^{1,2,3}$, BSc, PharmD, CACP; Sumaya Elgadi ${ }^{3,6}$, PharmD, MSc; Laila Carolina Abu Esba ${ }^{2,3,7}$, BSc, MSc, PharmD; Aeshah AlAzmi ${ }^{2,3,8}$, BSc, PharmD, SCSCP, FISQUA; Abrar Fahad Alhameed ${ }^{2,3,9}$, PharmD, BCPS, BCIDP; Ahmed Hattan ${ }^{2,3,7}$, PharmD; Saleh Almekhloof ${ }^{2,3,10}$, BSc, PharmD; Mohammed A AlShammary ${ }^{2,3,11}$, BSPharm; Nazzal Abdullah Alanezi ${ }^{2,3,12}$, BSHIM, MSHSA; Hani Solaiman Alhamdan ${ }^{3,8}$, BSc, MSc; Manal Eldegeir ${ }^{2,3,13}$, MBBS, MSc, MRCPCH, CCT; Rayf Abulezz ${ }^{2,3,9}$, BSc, PharmD, BCPS; Sahal Khoshhal ${ }^{2,3,9}$, BSc, MSc, PharmD; Clara Glynis Masala ${ }^{2,3,14}$, BA CUR; Omaima Ahmed ${ }^{2,3,15}$, MBBS

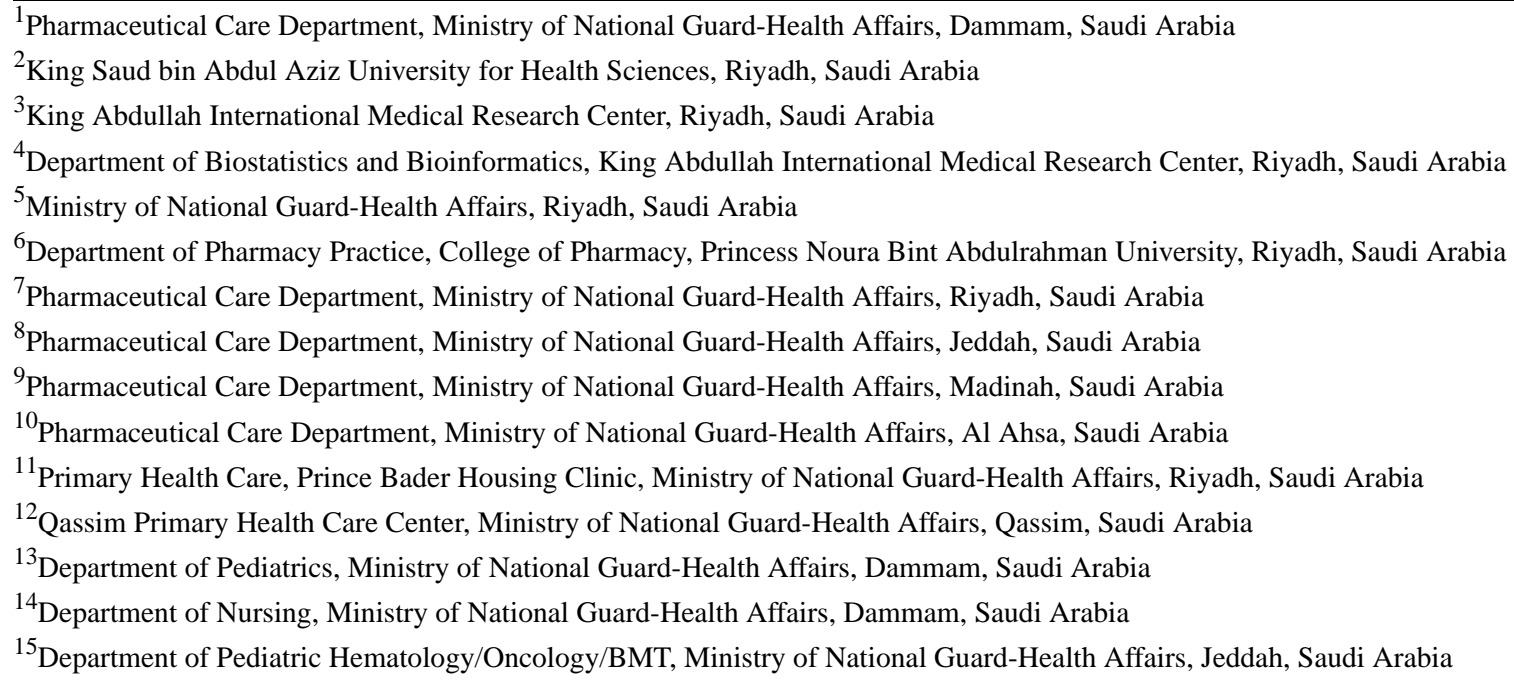

\section{Corresponding Author:}

Consuela Cheriece Yousef, PharmD, MPH, BCPS

Pharmaceutical Care Department

Ministry of National Guard-Health Affairs

PO Box 4616

Dammam, 31412

Saudi Arabia

Phone: 9668532555 ext 31680

Email: yousefco@ngha.med.sa

\section{Abstract}

Background: As health care organizations strive to improve health care access, quality, and costs, they have implemented patient-facing eHealth technologies such as personal health records to better engage patients in the management of their health. In the Kingdom of Saudi Arabia, eHealth is also growing in accordance with Vision 2030 and its National Transformation Program framework, creating a roadmap for increased quality and efficiency of the health care system and supporting the goal of patient-centered care.

Objective: The aim of this study was to investigate the adoption of the personal health record of the Ministry of National Guard Health Affairs (MNGHA Care).

Methods: A cross-sectional survey was conducted in adults visiting outpatient clinics in hospitals at the Ministry of National Guard Health Affairs hospitals in Riyadh, Jeddah, Dammam, Madinah, and Al Ahsa, and primary health care clinics in Riyadh and Qassim. The main outcome measure was self-reported use of MNGHA Care. 
Results: In the sample of 546 adult patients, 383 (70.1\%) reported being users of MNGHA Care. MNGHA Care users were more likely to be younger $(P<.001)$, high school or university educated $(P<.001)$, employed $(P<.001)$, have a chronic condition $(P=.046)$, use the internet to search for health-related information $(P<.001)$, and use health apps on their mobile phones $(P<.001)$.

Conclusions: The results of this study show that there is substantial interest for the use of MNGHA Care personal health record with $70 \%$ of participants self-reporting use. To confirm these findings, objective data from the portal usage logs are needed. Maximizing the potential of MNGHA Care supports patient engagement and is aligned with the national eHealth initiative to encourage the use of technology for high-quality, accessible patient-centered care. Future research should include health care provider perspectives, incorporate objective data, employ a mixed-methods approach, and use a theoretical framework.

(J Med Internet Res 2020;22(10):e22913) doi: $\underline{10.2196 / 22913}$

\section{KEYWORDS}

patient portal; personal health record; eHealth; Middle East; Saudi Arabia

\section{Introduction}

There has been exponential growth in internet penetration globally, including in Saudi Arabia where the internet penetration rate is $93 \%$ and that of social media is $72 \%$ [1]. Living in the digital age, an increasing number of patients are empowered, computer-literate, and have access to the internet. With advances in health information technology and the now ubiquity of the internet, patients have access to health information and are expected to engage in their care in new ways. Consumer-based health apps have been developed to "transform the paternalistic model of health care into one that is responsive to consumer needs and treats each individual as a copilot in a life-long health care process" [2].

The eHealth movement, which is the delivery of health services and information through the internet or related technology, has been broadly promoted to improve the health status of patients $[3,4]$. Patient-facing tools have been endorsed by the Institute of Medicine and the World Health Organization to encourage patient- and person-centered care by facilitating patient involvement in medical decision-making [5,6]. The use of digital information for disease and health-related tracking is widespread and considered an "essential and important element in the health care sector" [7]. Innovative eHealth technologies such as personal health records (PHRs) are leveraged to support patients in becoming empowered. Health care organizations adopt PHRs to increase patient engagement in the drive to meet the triple aims of health care: increase access, reduce cost, and improve quality of care [8-10].

PHRs are either standalone, tethered, or integrated [11]. A standalone PHR is owned by the patient and allows a person to "access and coordinate their lifelong health information" [12]. A tethered PHR, or patient portal, is connected to an organization's electronic health record (EHR) and allows patients to access information from their medical records [13]. An integrated PHR contains patient information from various sources such as pharmacy data, insurance claims, and an EHR. PHR features vary among health care organizations. Basic PHR features include viewing lab results, requesting prescription refills, and scheduling appointments $[8,14,15]$. More advanced PHR features include personal health-related reminders, secure messaging, eVisits, and social networking [16]. Since the terms "PHR" and "patient portal" have been used interchangeably in the literature, we here consider the two terms to be synonymous [9].

PHRs are designed to increase patient engagement in managing their health, increase care coordination, and to encourage patient empowerment [16-18]. Engaged patients monitor and update their medication and there is potentially more treatment concordance, leading to positive health outcomes [17,19]. Patient engagement is increasingly recognized as a vital component of safe, person-centered care [6]. Providing patients with access to their EHRs through a PHR is a method for health care systems to promote engagement [20].

Previous studies have shown that PHR use has positive effects on patient adherence, patient self-management skills, and clinical outcomes [16,19,21]. Wade-Vuturo et al [21] found that patients with diabetes mellitus who used a patient portal had better patient-provider communication, more satisfaction with care, greater self-management behaviors, and improved clinical outcomes (ie, hemoglobin A1c, hospital admissions, and emergency room visits). The PHR could bridge the gap due to the limited time and planning devoted to addressing chronic needs since acute issues are the focus of health care visits [22]. Despite the proposed benefits and consumer interest in PHRs, various studies have shown limited adoption and use [8,9,23-25]. According to Abd-Alrazaq et al [8], PHR adoption ranged from $0.13 \%$ in the United Kingdom to $10 \%$ in the United States.

PHRs are relatively new in the Middle East with less than $12 \%$ of health care organizations in the Arab world offering them [26]. Health care organizations in the Kingdom of Saudi Arabia (KSA) have only recently begun to implement PHRs. As with many developed countries, the KSA has invested substantial resources in the implementation of eHealth systems to reduce health care costs and improve care with 4 billion Saudi Arabian Riyals (SAR; US $\$ 1.1$ billion) allocated by the government to improve eHealth [27]. The KSA has dedicated enormous funds to enhance national health care systems. To that end, the health care system is one of the priority areas of the National Transformation Program 2020 and Saudi Vision 2030, aiming to provide the highest quality of health care services to the citizens and residents while providing sufficient and efficient health care. The national eHealth initiative focused on improving the quality and efficiency of health care services by enhancing a patient-centered health care culture and increasing patient involvement in their care through technology [28]. In line with 
the KSA's eHealth agenda, research on eHealth tools such as PHRs has grown [18,29-32].

The main objectives of this study were as follows: (1) to examine the prevalence of PHR use by region, (2) to categorize the PHR features used most frequently, and (3) to identify predictors of PHR adoption by patients. In addition, comparisons were made between portal users and nonusers according to (1) demographic and clinical characteristics, (2) access to and use of the internet, (3) health literacy and self-reported health status, and (4) online health-related information-seeking behavior.

Research into the actual use of the PHR focusing on the users and features accessed will lay the foundation for future developments of the system and targeted efforts to motivate patients to adopt its use. To reap the proposed benefits and maximize the return on investment, research must be conducted with an eye toward contextual factors and finding methods to promote initial and sustained PHR use among all patient populations.

\section{Methods}

\section{Study Setting}

The Ministry of National Guard Health Affairs (MNGHA) is a large tertiary health care system established in 1983 to provide state-of-the-art medical care to the National Guard's soldiers and their dependents in all regions across the KSA [33]. The MNGHA is a leader in health care services in the Middle East. As a health care leader, MNGHA implemented its PHR known as MNGHA Care in 2018. Some of the features available in MNHGA Care include scheduling appointments, requesting medical reports, viewing radiology reports, checking laboratory results, requesting prescription refills, and providing vaccination reminders. MNHGA Care allows patients to upload personal health information such as weight, blood pressure, blood sugar, and exercise details. There is also a self-assessment feature where patients can enter information on pain control, performance status, and quality of life. In addition, it contains links to health educational information. MNGHA Care is a powerful tool that is expected to increase health awareness and promote positive health outcomes [34].

\section{Study Design}

A cross-sectional survey design was used. An online survey was constructed and administered through QuestionPro. The study was conducted from December 2019 to February 2020.

\section{Sample}

The target population consisted of adults who visited the outpatient waiting areas at Imam Abdulrahman Bin Faisal Hospital in Dammam, King Abdulaziz Medical City in Riyadh, King Abdulaziz Medical City in Jeddah, Prince Mohammad Bin AbdulAziz Hospital in Madinah, King Abdulaziz Hospital in Al Ahsa, and the primary health clinics in Riyadh and Qassim. The study was carried out at each site independently with each site's research team. Patients or their caregivers were eligible to participate if they were aged 18 years and older and able to read and understand either Arabic or English.

\section{Sampling Strategy}

Stratified random sampling with proportionate allocation was used to draw samples from the study population. The approximate number of patients seen daily in each city was used to determine the target sample for each site. Table 1 shows the proportionate allocation by city with the sample selected in proportion to the size of the population. Since no sampling frame was available, the biostatistician generated a random day and time schedule to be used by each site when beginning data collection.

Table 1. Proportionate allocation by region.

\begin{tabular}{lll}
\hline Region & Approximate number of patients/day & Minimum N \\
\hline Dammam & 250 & 27 \\
Riyadh & 1120 & 139 \\
Jeddah & 850 & 75 \\
Medina & 200 & 22 \\
Al Ahsa & 750 & 80 \\
\hline
\end{tabular}

\section{Sample Size}

The effect size was based on $40 \%$ internet usage for Usenet, listserv, discussion forums, internet phone, and streaming audio music [35]. This effect size was then applied to find the optimal sample size to detect a proportion of the Saudi population using the internet with a predefined accuracy. We assumed the minimum weekly visit frequency as the population to calculate the overall sample sizes. We further adjusted the sample size according to the proportion of daily visits in each region. With the above assumptions, the study required at least 364 complete records to estimate the proportion at a $95 \%$ confidence limit and within $5 \%$ precision.

\section{Participant Recruitment}

Each research site used the survey time points and days from the table prepared prior to study initiation. A member of the research team recruited participants in the outpatient pharmacy waiting areas and used a password-protected device to allow the participants to access the survey through QuestionPro, provide consent, and complete the survey. All participants were informed about the study purpose, and were assured anonymity and confidentiality of the information collected. The research team member approached the subjects at randomly selected time points during active working hours until the minimum sample size requirement for the center was reached. 


\section{Instrument}

This study used a questionnaire developed by the lead author based on a literature review. The questionnaire contained 41 questions covering demographics, health status, satisfaction with health care, health literacy, mobile phone and internet usage, online health-related information-seeking behavior, and MNGHA Care. There were 13 statements rated on a Likert scale related to MNGHA Care use included but not analyzed for this study. The authors reviewed the questions to ensure readability and appropriateness. The questionnaire was forward-translated by native Arabic speakers and was back-translated by a professional translator and compared to the original. Before study initiation, a pilot test was performed in 20 volunteers at Imam Abdulrahman Bin Faisal Hospital with slight modifications made.

\section{Measures}

Demographic and clinical characteristics were collected to describe the study sample and were self-reported. Demographic characteristics included health care facility, age, gender, marital status, educational level, employment status, and monthly household income. Clinical characteristics included the presence of a medical condition, number and type of medical conditions, self-reported health status, recent hospitalization ( $<6$ months), recent emergency department visit ( $<6$ months), and satisfaction with health care.

To characterize mobile phone and internet usage, one question was asked about smartphone ownership and another question was asked about the frequency of internet use.

Previous researchers have identified a link between health literacy and technology use [36,37].

Therefore, a single-item health literacy screener was used with the following question: "How often do you need to have someone help you when you read instructions, pamphlets, or other written material from your doctor or pharmacy?" [38].

Four questions were related to internet use for seeking health information: (1) Do you use the internet to search for medical information? (2) Are you a member of an online health community? (3) Do you discuss health issues on social media (eg, Facebook, Twitter)? (4) Do you use health apps on your mobile phone?

\section{Outcome}

The outcome variable was the patient-reported use of the PHR, operationalized by asking the patients whether or not they used MNGHA Care.

\section{Ethics Statement}

All participants were informed about the aim of the study and their right to not answer any question they felt uncomfortable answering. The study was approved by the Institutional Review Board (RD19/002/D) at King Abdullah International Medical Research Center in Riyadh, Saudi Arabia.

\section{Data Analysis}

The raw data were downloaded from QuestionPro into Microsoft Excel and were analyzed using SAS 9.4. The proportion of PHR users with the corresponding 95\% confidence limit was calculated using the Wilson score method. Descriptive analysis was used to summarize the categorical variables as frequency and percentage and continuous variables as mean and standard deviation. For reporting convenience, the continuous variables were grouped and the frequency and percentage are reported in each group. Further, we compared the relative frequency distribution of all variables across PHR users and nonusers. The chi-square test was used to measure the significance of the association between individual covariates and PHR usage. Finally, multiple logistic regression was used to estimate the odds ratio and the corresponding 95\% confidence limit. Throughout the study, we considered any $P$ value less than .05 as evidence for a significant result.

\section{Results}

\section{Sample Characteristics}

The baseline characteristics of the participants are shown in Table 2. A total of 546 participants agreed to complete the survey. Most of the participants were men, married, employed, and university graduates. The mean age was 37.39 (SD 11.23) years. The estimated monthly income was greater than 5000 SAR/month (US $\$ 1333 /$ month) for $68.0 \%$ (335/493) of the participants. Most participants rated their health as very good or excellent. The majority reported only one medical condition. The most frequently reported medical conditions were diabetes, hypertension, and asthma or chronic obstructive pulmonary disease. About a quarter of the sample reported being hospitalized and approximately half had visited the emergency department in the previous 6 months. All patients were either satisfied or very satisfied with their health care. Most patients either never or rarely need help with reading materials from their physician or pharmacist. 
Table 2. Baseline demographics of participants $(\mathrm{N}=546)$.

\begin{tabular}{|c|c|}
\hline Variable & $\mathrm{n}(\%)$ \\
\hline \multicolumn{2}{|l|}{ Age (years) } \\
\hline $18-29$ & $133(26.3)$ \\
\hline $30-39$ & $170(33.6)$ \\
\hline $40-50$ & $104(20.6)$ \\
\hline$>50$ & $99(19.57)$ \\
\hline Male & $280(53.3)$ \\
\hline \multicolumn{2}{|l|}{ Health care facility } \\
\hline King Abdulaziz Medical City (Riyadh) & $118(21.6)$ \\
\hline King Abdullah Specialized Children's Hospital (Riyadh) & $35(6.4)$ \\
\hline Primary Health Clinic (Riyadh) & $32(5.9)$ \\
\hline King Khaled National Guard Hospital (Jeddah) & $124(22.7)$ \\
\hline Prince Mohammed Bin Abdulaziz Hospital (Madinah) & $32(5.9)$ \\
\hline King Abdulaziz Hospital (Al Ahsa) & $145(26.6)$ \\
\hline Imam Abdulrahman Bin Faisal Hospital (Dammam) & $27(4.9)$ \\
\hline Primary Health Clinic (Qassim) & $33(6.0)$ \\
\hline Married & $426(78.9)$ \\
\hline \multicolumn{2}{|l|}{ Education } \\
\hline Elementary or less & $65(11.9)$ \\
\hline Middle school & $44(8.1)$ \\
\hline High school & $177(32.6)$ \\
\hline University & $233(41.1)$ \\
\hline Postgraduate & $34(6.3)$ \\
\hline Employed & $273(45.3)$ \\
\hline \multicolumn{2}{|l|}{ Health status } \\
\hline Excellent & $224(41.0)$ \\
\hline Very good & $188(34.3)$ \\
\hline Good & $94(17.2)$ \\
\hline Fair & $27(5.0)$ \\
\hline Poor & $13(2.4)$ \\
\hline \multicolumn{2}{|l|}{ Number of medical conditions } \\
\hline 0 & $152(27.9)$ \\
\hline 1 & $280(51.5)$ \\
\hline$\geq 2$ & $112(20.6)$ \\
\hline \multicolumn{2}{|l|}{ Type of medical condition } \\
\hline Diabetes & $118(21.6)$ \\
\hline Hypertension & $104(19.0)$ \\
\hline Asthma or COPD ${ }^{\mathrm{a}}$ & $60(11.0)$ \\
\hline \multicolumn{2}{|l|}{ Satisfaction with health care } \\
\hline Very satisfied & $502(92.5)$ \\
\hline Satisfied & $41(7.6)$ \\
\hline Hospitalized within the last 6 months & $133(24.4)$ \\
\hline Visited the emergency department within the last 6 months & $249(45.9)$ \\
\hline
\end{tabular}




\begin{tabular}{lc}
\hline Variable & $\mathrm{n}(\%)$ \\
\hline Need help with reading instructions & $334(61.2)$ \\
Never & $110(20.1)$ \\
Rarely & $81(14.9)$ \\
Sometimes & $16(2.9)$ \\
Often & $4(0.7)$ \\
Always & \\
\hline
\end{tabular}

${ }^{\mathrm{a} C O P D}$ : chronic obstructive pulmonary disease.

\section{Internet Use and Online Health Information-Seeking Behavior}

Table 3 shows data from the survey related to internet use and online health information-seeking behavior. An overwhelming majority of the participants reported using a smartphone and accessing the internet several times a day. A large majority also reported using the internet to search for medical information. However, relatively few participants reported being a member of an online health community or discussing health issues on social media. Over half the participants use health apps on their mobile phones.

Table 3. Internet use and online health information-seeking behavior $(\mathrm{N}=546)$.

\begin{tabular}{ll}
\hline Internet use category & $\mathrm{n}(\%)$ \\
\hline Smartphone use & $516(94.5)$ \\
Frequency of internet use & $442(81.0)$ \\
$\quad$ Several times a day & $30(5.5)$ \\
$\quad$ About once daily & $19(3.5)$ \\
$\quad$ A few times per week & $22(4.0)$ \\
$\quad$ A few times per month & $29(5.3)$ \\
$\quad$ Rarely or not at all & $381(69.8)$ \\
Use the internet to search for medical information & $44(8.1)$ \\
Member of online health community & $101(18.5)$ \\
Discuss health issues on social media & $299(54.8)$ \\
Use health apps on your mobile phone &
\end{tabular}

\section{MNGHA Care Use}

Of the 546 participants, $460(84.7 \%)$ were aware of MNGHA Care. As shown in Table 4, most participants were made aware of MNGHA Care through someone from the organization-health care provider or other hospital staff-followed by a family member. Of the 460 participants aware of the PHR, $383(83.3 \%)$ reported using it. The health care facilities were classified into the central (Riyadh and Qassim), eastern (Al Ahsa and Dammam), and western (Jeddah and Madinah) regions. There was a statistically significant difference in use by region $(P<.001)$ : central region $(182 / 383$, $47.5 \%)$, eastern region $(109 / 383,28.5 \%)$, and western region $(92 / 383,24.0 \%)$. In response to the question "How long have you been using MNGHA Care?", the majority of respondents $(267 / 383,69.7 \%)$ reported using it for the past 12 months with most $(160 / 383,41.8 \%)$ using it only within the last 6 months. Most participants reported using MNGHA Care a few times a month $(210 / 383,54.8 \%)$ to rarely $(119 / 383,31.1 \%)$. PHR features accessed by the participants are shown in Figure 1. Scheduling appointments was the feature used most frequently in all regions. In the western region, use of the PHR to check laboratory results was quite low $(6.5 \%)$ compared to that reported in the eastern region (48.6\%) and central region $(34.1 \%)$. Prescription refill requests were used the most in the eastern region $(38.5 \%)$, followed by the western region $(22.8 \%)$ and central region $(15.9 \%)$. 
Table 4. Source of MNGHA Care recommendation among users ( $\mathrm{N}=383)$.

\begin{tabular}{ll}
\hline Recommender & $\mathrm{n}(\%)$ \\
\hline Health care provider & $179(46.7)$ \\
Other hospital staff & $41(10.7)$ \\
Family & $90(23.5)$ \\
Friends & $47(12.3)$ \\
No one & $20(5.2)$ \\
\hline
\end{tabular}

Figure 1. MNGHA Care features accessed by region.

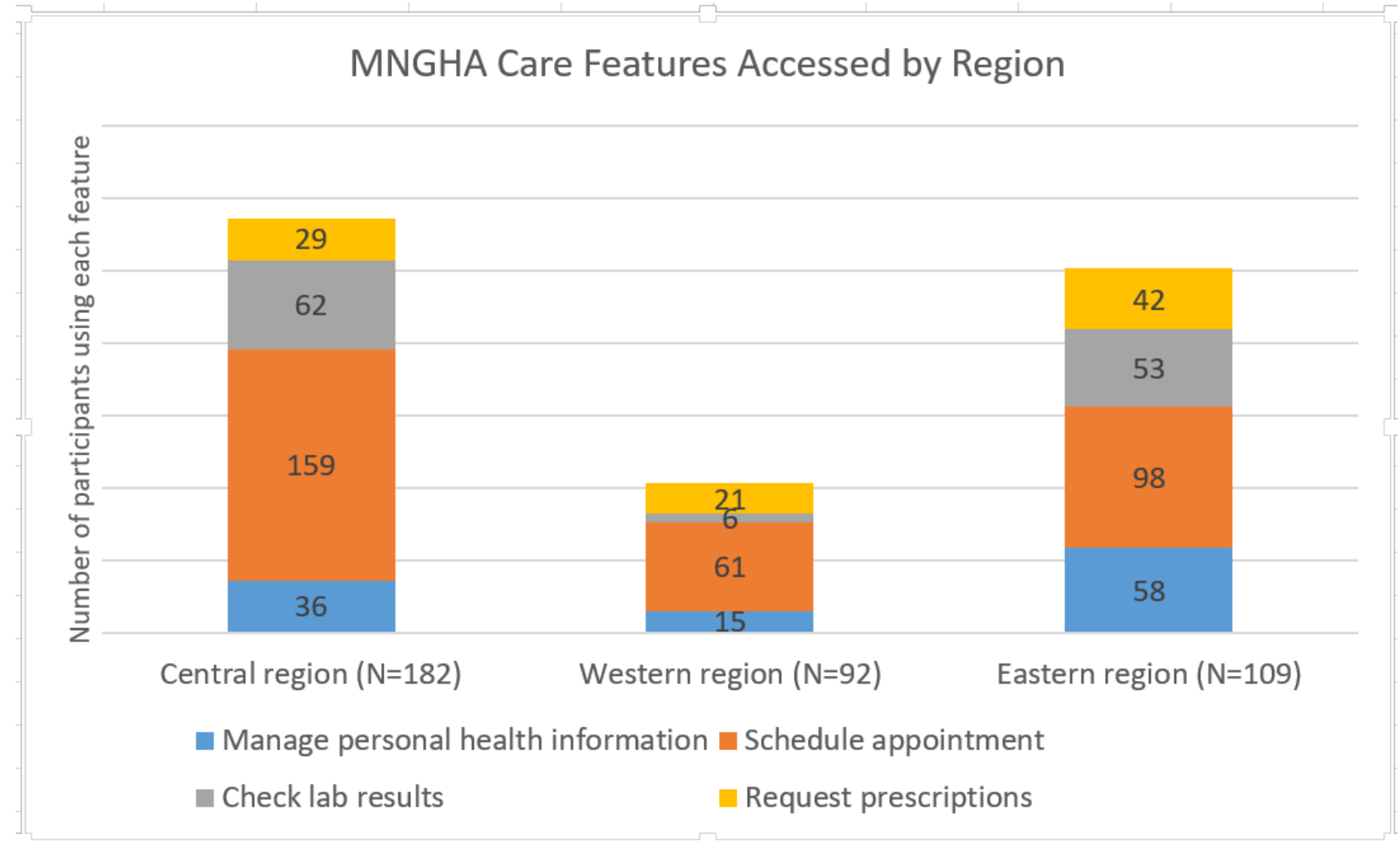

Table 5 shows a comparison of the baseline demographics between MNGHA Care users and nonusers. There were statistically significant differences between the groups with respect to age, educational level, and employment status.
MNGHA Care users were younger (18-39 years), had a high school or university education, had at least one medical condition, and larger monthly household incomes relative to those of nonusers. 
Table 5. Demographic characteristics of personal health record (PHR) users and nonusers.

\begin{tabular}{|c|c|c|c|}
\hline Characteristic & PHR user, n (\%) & PHR nonuser, n (\%) & $P$ value \\
\hline Age group $(\mathrm{N}=487)$ & & & .001 \\
\hline $18-29$ years & $102(33.0)$ & $30(21.3)$ & \\
\hline $30-39$ years & $128(41.4)$ & $42(29.8)$ & \\
\hline $40-49$ years & $79(22.8)$ & $25(17.7)$ & \\
\hline$\geq 50$ years & $37(10.7)$ & $44(31.2)$ & \\
\hline Gender $(N=523)$ & & & .44 \\
\hline Male & $194(52.4)$ & $88(56.2)$ & \\
\hline Female & $176(47.6)$ & $67(43.8)$ & \\
\hline Marital status $(\mathrm{N}=537)$ & & & .30 \\
\hline Married & $303(80.2)$ & $121(76.1)$ & \\
\hline Unmarried & $75(19.8)$ & $38(23.9)$ & \\
\hline Educational level $(\mathrm{N}=540)$ & & & $<.001$ \\
\hline Elementary school or less & $26(6.8)$ & $38(23.9)$ & \\
\hline Middle school & $25(6.6)$ & $18(11.3)$ & \\
\hline High school & $139(36.5)$ & $38(23.9)$ & \\
\hline University & $167(43.8)$ & $55(34.6)$ & \\
\hline Postgraduate & $24(6.3)$ & $10(6.3)$ & \\
\hline Monthly household income ( $\mathbf{N}=490)$ & & & .11 \\
\hline$<1333$ US \$/month & $105(30.1)$ & $54(37.6)$ & \\
\hline 1333-2665 US \$/month & $118(33.8)$ & $50(35.5)$ & \\
\hline >2666 US \$/month & $127(36.1)$ & $38(27.0)$ & \\
\hline Employment status $(\mathrm{N}=536)$ & & & $<.001$ \\
\hline Employed & $207(54.6)$ & $59(37.6)$ & \\
\hline Unemployed & $115(30.3)$ & $55(35.0)$ & \\
\hline Retired & $36(9.5)$ & $34(21.7)$ & \\
\hline Student & $21(5.5)$ & $9(5.7)$ & \\
\hline
\end{tabular}

Table 6 compares MNGHA Care users and nonusers according to health status. Importantly, the frequency of users among those with a medical condition was more than double that of users without a medical condition, representing a significant difference between users and nonusers according to medical condition. 
Table 6. Health status of MNGHA Care users and nonusers.

\begin{tabular}{|c|c|c|c|}
\hline Question & Users & Nonusers & $P$ value \\
\hline How do you rate your health? $(\mathrm{N}=543)$ & & & $<.001$ \\
\hline Poor & $5(1.3)$ & $8(5.0)$ & \\
\hline Fair & $13(3.4)$ & $14(8.8)$ & \\
\hline Good & $54(14.1)$ & $39(24.4)$ & \\
\hline Excellent & $170(44.4)$ & $53(33.1)$ & \\
\hline Do you have any medical condition? $(\mathrm{N}=541)$ & & & .046 \\
\hline Yes & $265(69.4)$ & $124(78.0)$ & \\
\hline No & $117(30.6)$ & $35(22.0)$ & \\
\hline Number of medical conditions $(\mathrm{N}=541)$ & & & .002 \\
\hline 0 & $117(30.6)$ & $35(22.0)$ & \\
\hline 1 & $201(52.6)$ & $77(48.4)$ & \\
\hline$\geq 2$ & $64(16.8)$ & $47(29.6)$ & \\
\hline Hospitalized within the last 6 months $(\mathrm{N}=542)$ & & & .04 \\
\hline Yes & $84(21.9)$ & $49(30.8)$ & \\
\hline No & $299(78.1)$ & $110(69.2)$ & \\
\hline \multicolumn{3}{|c|}{ Visited the emergency department within the last 6 months $(N=545)$} & .51 \\
\hline Yes & $179(47.1)$ & $70(43.8)$ & \\
\hline No & $201(52.9)$ & $90(56.3)$ & \\
\hline
\end{tabular}

Table 7 compares MNGHA Care users and nonusers according to health literacy and online health-related information-seeking behavior. There were statistically significant differences in PHR

use in those who use the internet to search for medical information $(P<.001)$ and in those who use health apps on their mobile phone $(P<.001)$. 
Table 7. Health literacy and online health information-seeking behavior.

\begin{tabular}{|c|c|c|c|}
\hline Question & PHR ${ }^{\mathrm{a}}$ users, $\mathrm{n}(\%)$ & PHR nonusers, $\mathrm{n}(\%)$ & $P$ value \\
\hline $\begin{array}{l}\text { How often do you need to have someone help you when you read instructions, pam- } \\
\text { phlets, or other written material from your doctor or pharmacy? }(\mathrm{N}=539)\end{array}$ & & & .47 \\
\hline Never & $230(60.1)$ & $102(64.2)$ & \\
\hline Rarely & $85(22.2)$ & $25(15.7)$ & \\
\hline Sometimes & $53(13.8)$ & $27(17.0)$ & \\
\hline Often & $12(3.1)$ & $4(2.5)$ & \\
\hline Always & $3(0.8)$ & $1(0.6)$ & \\
\hline Do you use the internet to search for medical information? $(\mathrm{N}=543)$ & & & $<.001$ \\
\hline Yes & $303(79.1)$ & $77(48.1)$ & \\
\hline No & $80(20.9)$ & $83(51.9)$ & \\
\hline Are you a member of an online health community? $(\mathrm{N}=542)$ & & & .61 \\
\hline Yes & $33(8.6)$ & $11(6.9)$ & \\
\hline No & $350(91.4)$ & $148(93.1)$ & \\
\hline Do you discuss health issues on social media (e.g., Facebook, Twitter) $(\mathrm{N}=541)$ & & & .07 \\
\hline Yes & $79(20.7)$ & $22(13.8)$ & \\
\hline No & $302(79.3)$ & $138(86.3)$ & \\
\hline Do you use health apps on your mobile phone? $(\mathrm{N}=533)$ & & & $<.001$ \\
\hline Yes & $250(65.6)$ & $48(31.6)$ & \\
\hline No & $131(34.4)$ & $104(68.4)$ & \\
\hline
\end{tabular}

${ }^{\mathrm{a}} \mathrm{PHR}$ : personal health record.

Table 8 shows the logistic regression results assessing the influence of various participant characteristics on MNGHA Care use. Of the 9 predictor variables, only 3 were statistically significant: educational level, use of the internet to search for health-related information, and use of health apps on the mobile phone. Although higher educational level was associated with more frequent PHR use, this relationship was only statistically significant for patients with a high school education, who had a 4.08-times higher odds of using the PHR compared with those having an elementary education $(P=.002)$. Patients who use the internet to search for health-related information had a 2.4-times higher odds of using the PHR $(P=.005)$. Finally, patients who use health apps on their mobile phones had a 2.1-times higher odds of using the PHR $(P=.008)$. 
Table 8. Predictors of MNGHA Care use.

\begin{tabular}{|c|c|c|}
\hline Variable & Odds ratio $(95 \% \mathrm{CI})$ & $P$ value \\
\hline Female & $1.426(0.739-2.750)$ & .29 \\
\hline \multicolumn{3}{|l|}{ Age (years) } \\
\hline $18-29$ & Reference & \\
\hline $30-39$ & $0.738(0.335-1.628)$ & .59 \\
\hline $40-49$ & $0.657(0.258-1.672)$ & .99 \\
\hline$\geq 50$ & $0.378(0.129-1.105)$ & .08 \\
\hline \multicolumn{3}{|l|}{ Employment status } \\
\hline Unemployed & Reference & \\
\hline Employed & $1.083(0.457-2.569)$ & .39 \\
\hline Retired & $0.703(0.241-2.051)$ & .65 \\
\hline Student & $0.640(0.182-2.250)$ & .58 \\
\hline \multicolumn{3}{|l|}{ Household income (US \$/month) } \\
\hline$<1333$ & Reference & \\
\hline $1333-2665$ & $1.044(0.491-2.222)$ & .53 \\
\hline$>2666$ & $1.571(0.641-3.849)$ & .23 \\
\hline \multicolumn{3}{|l|}{ Region } \\
\hline Central & Reference & \\
\hline Eastern & $0.199(0.098-0.406)$ & .09 \\
\hline Northern & $0.521(0.088-3.081)$ & .49 \\
\hline Southern & $0.148(0.038-0.567)$ & .14 \\
\hline Western & $0.225(0.105-0.480)$ & .22 \\
\hline \multicolumn{3}{|l|}{ Education } \\
\hline Elementary school or less & Reference & \\
\hline Middle school & $2.29(0.695-7.549)$ & .58 \\
\hline High school & $4.08(1.428-11.662)$ & .002 \\
\hline University & $1.825(0.590-5.646)$ & .99 \\
\hline Postgraduate & $1.170(0.267-5.138)$ & .33 \\
\hline \multicolumn{3}{|l|}{ Number of medical conditions } \\
\hline 0 & Reference & \\
\hline 1 & $1.323(0.722-2.425)$ & .95 \\
\hline$\geq 2$ & $1.695(0.740-3.88)$ & .28 \\
\hline Internet use for health-related information & $2.448(1.32-4.539)$ & .005 \\
\hline Health apps on mobile phones & $2.069(1.209-3.539)$ & .008 \\
\hline
\end{tabular}

\section{Discussion}

\section{Principal Findings}

In the sample of 546 adult patients, $383(70.1 \%)$ reported being users of MNGHA Care. The central region (Riyadh and Qassim) had higher use (83.4\%) than the western (Jeddah and Madinah, $59.4 \%$ ) or eastern (Dammam and $\mathrm{Al}$ Ahsa, 64.1\%) regions. There were 460 participants $(84.6 \%)$ who were aware of the PHR. Of those, the majority $(83.3 \%)$ reported using MNHGHA Care. Despite the high penetration of internet (93\%) and social media $(72 \%)$ use in the KSA, few participants reported being a member of an online health community (8.0\%) or discussing health issues on social media (18.6\%), whereas a high proportion of participants reported using the internet to seek health information [1]. Other researchers in the KSA have found a growing interest in patients using online social networking for health-seeking purposes [39-41].

Prior to the implementation of MNGHA Care in 2018, Al-Sahan and Saddik [31] conducted a study among 424 patients in the outpatient setting at MNGHA Riyadh to gauge the acceptance of the PHR. In their study, most patients were interested (25.2\%) or very interested $(60.6 \%)$ in a PHR. The results of this study 
appear to be concordant with these previous findings, even though their sample was predominantly female $(68.2 \%)$ with the majority having no medical condition (68.2\%). Technology use was also evaluated, demonstrating high internet use (95.9\%), smart device use (92.2\%), and computer use (80.7\%), with only $15.9 \%$ accessing patient electronic services from the MNGHA website (15.9\%). Our study showed similar findings with $94.5 \%$ having a smartphone and $81 \%$ using the internet several times a day.

MNGHA Care users were more likely to be younger (18-39 years of age), high school or university educated, employed, users of the internet to search for health-related information, and users of health apps on their mobile phones. Most PHR studies have been conducted in Western countries and have noted differences in PHR use by age, gender, and ethnic background, with people of a lower socioeconomic status using PHRs less often [19,42-47]. In the systematic review conducted by Abd-Alrazaq et al [8], the factors positively associated with use of a PHR were awareness of the PHR, perceived ease of use, perceived usefulness, internet access, income, and education level. Our study also showed a positive association of PHR use with awareness, internet access, income, and educational level.

Our results indicated that increasing age is associated with lower odds of using the PHR. This is consistent with the existing literature [44,46,48-51]. Even though older patients have more chronic conditions and are in the greatest need of support in disease self-management, many do not use a PHR for a variety of reasons. Disparities in PHR use by age have frequently been cited in the literature with many studies showing that older individuals are less likely to use a PHR. Confounding factors include low computer literacy, low eHealth literacy, or less inclination to use technology, ultimately leading to more difficulties with advanced technologies such as PHRs $[17,32,48]$. In a study using a simulated PHR in adults aged 40 years and above, the authors concluded that adults with age-related declines in reasoning and cognitive abilities were more likely to have difficulties completing more complex health management tasks using a PHR [52]. In a study conducted in Saudi Arabia using a simulated PHR to perform various health management tasks, the authors found an increased probability to watch the help video with each 1-year increase in age, but did not note difficulties by age in completing simple compared to complex tasks [32]. The authors suggested embedding aids such as help videos in PHRs to improve the comprehension of numeric health information [53]. Special considerations should be made in the design of a PHR with targeted training sessions for the older population. Allowing patients to participate in the design of the PHR through focus groups is a strategy employed by some health care organizations [50].

Another area where the digital divide has been evident with the use of PHRs relates to education level [9,42,54]. Our study showed that a high school or university education was associated with use of the PHR; however, there was no difference in use for those with a postgraduate degree. This is inconsistent with previous research, which has shown increasing PHR use with higher levels of education. In the systematic review conducted by Zhao et al [9] examining barriers and facilitators to PHR use, the authors recognized that one of the most common barriers is lack of a user-friendly interface. They identified 17 studies that mentioned redesigning the PHR and patient portal interfaces so that they are "easy-to use, easy-to-navigate interfaces and simpler language" [9]. Honein-AbouHaidar et al [26] evaluated the acceptance of the patient portal in Lebanon and noted the importance of simplifying and tailoring messages to the target population. Focusing on the patients and how the information is presented in the PHR will prevent the widening of health disparities.

Other studies have found that patients with chronic medical conditions are more frequent PHR users than those without $[26,44,51,55]$. In this study, $389(71.9 \%)$ of the participants had a medical condition, $265(68.1 \%)$ of whom reported using MNGHA Care. Similar to the literature, patients with a chronic medical condition had a higher prevalence of PHR use. Diabetes mellitus was the most frequently reported medical condition in our participants. Numerous studies have evaluated PHR use in this population to improve diabetes care, increase self-management, and optimize health outcomes [14,21,37,49,56-61]. Belcher et al [29] conducted a 12-week study in 31 patients with diabetes mellitus in the eastern province of Saudi Arabia who were sent twice-weekly messages through the patient portal. They found a reduction in hemoglobin A1c (11\% to $9 \%)$ and fasting blood sugar (198 to $173 \mathrm{mg} / \mathrm{dL})$. Secure messaging, a feature not available in MNGHA Care, has been associated with improved glycemic control in studies of PHR use in patients with diabetes mellitus [13]. In the study by Al Sahan and Sadek [31], 74.1\% of participants reported a desire to communicate with a physician. Since patients showed an interest in secure messaging and studies have shown positive patient outcomes, it may be the right time to consider adding this feature in phases across the organization to support patient-centered communication.

This study showed that the MNGHA Care feature used most commonly was appointment scheduling (83.0\%). In the study by Al Sahan and Sadek [31], participants were interested in accessing laboratory results $(91.7 \%)$, radiology results $(82.9 \%)$, and appointment scheduling $(90.5 \%)$. With real-world use, our participants underutilized the features for managing personal health information $(28.5 \%)$, checking laboratory results (31.6\%), and requesting prescription refills $(24.0 \%)$. Although the previous study showed a high level of patient interest in specific PHR features 2 years before MNGHA Care was implemented in the organization, utilization was less than would be expected after the implementation. Indeed, interest in PHRs and their features has been found to be higher than the actual adoption, with $80 \%$ of US respondents surveyed indicating interest in PHRs but only $2.2 \%$ of the population actually used a PHR [53]. Having the technology available is one challenge to be overcome but it is also necessary to monitor the process, find ways to connect patients to the technology, and investigate their concerns regularly postimplementation.

An explanation for the low percentage of participants requesting prescription refills is that the pharmacies in each region chose when to activate this feature. Not all pharmacies in all regions had activated the refill function at the time of performing this study. With respect to checking laboratory results and managing personal information, patients may have disliked the interface 
or had problems interacting with the system. Zhao et al [9] highlighted the need for health care providers to work with patients and demonstrate the features as a way to increase the value of the PHR from the patients' perspective. There also could have been differences in the way the PHR was rolled out in each region. The central region possibly implemented more strategies aimed at encouraging patient awareness compared to the other regions. Finally, it is recognized that health care providers play an influential role in endorsing PHR use $[8,9,44,47]$. This is evident in our study, in which the health care provider $(47.9 \%)$ or hospital staff $(10.8 \%)$ was responsible for recommending the use of MNGHA Care to most participants. For better utility of the PHR, all health care providers and staff need proper training to support their patients. It is hoped that an impact of this study will be to disseminate information on the availability and benefits of the PHR and its various functions to patients and health care providers.

\section{Limitations}

A major limitation of this study is the use of only self-reported data. Several biases are associated with self-reported data, including social desirability, recall, and nonresponse bias [62]. There may have been overreporting of PHR use by participants because they felt that this was the answer expected of them. In the systematic literature review and meta-analysis conducted by Fraccaro et al [25], the researchers found an adoption rate of $71 \%$ in controlled experiments and $23 \%$ in real-world experiments. In a cross-sectional study conducted in the Netherlands, there was a $32.1 \%$ adoption rate [44]. Objective PHR data from system usage logs can be used along with self-reported data; however, such data were not available to the research team for this study. Systems data would provide information on the total MNGHA population registered to use the PHR, patient logins, and use of specific features. In addition, those who agreed to participate may have been more likely to use MNGHA Care compared with those who did not participate, resulting in skewed results. Another limitation is the use of only a quantitative approach for analysis. This study would have benefited from combining quantitative data with qualitative data in a mixed-methods approach. The advantage would be gaining greater insight into patient acceptance and concerns with use of MNGHA Care. Such analysis would allow for a more in-depth examination of some of the barriers and facilitators to adoption within the KSA. Another limitation is that the study was conducted in a single health system. However, the large sample size of patients from across the country who were visiting different departments should increase the generalizability of the findings. Finally, the lack of a theoretical framework possibly limits the interpretation of interrelationships between patient factors and PHR characteristics.

\section{Conclusions}

The results of this study show that there is a great deal of interest in use of MNGHA Care with 70\% of participants self-reporting use. To our knowledge, this study is the first to report on the adoption of a PHR in a real-world setting in the KSA. To confirm these findings, objective data from the portal usage logs are needed. With the COVID-19 pandemic, the entire world is learning many lessons as the eHealth landscape transforms rapidly. One lesson we are learning is how to engage in health care remotely and efficiently via electronic apps. Remote personal health engagement has become the new normal. Maximizing the potential of MNGHA Care supports patient engagement and is aligned with the national eHealth initiative to encourage the use of technology for high-quality, accessible patient-centered care. Future research should include health care provider perspectives, incorporate objective data, employ a mixed-methods approach, and use a theoretical framework.

\section{Acknowledgments}

The authors would like to thank the data collectors Aliya Najeeb Balbaid, Raneem Mohammad Aljohani, Faten Mohammed Alasiri, Mahmoud Ismail Nouh, and Ismail Hasanin. We also greatly appreciate the assistance of the research coordinators Nadia Alotaibi, Mohammed Al Arab, and Dr. Shahinaz Bashir. Finally, we thank Marjorie Palcat for her administrative assistance at King Abdullah International Medical Research Center, Dammam.

\section{Conflicts of Interest}

None declared.

\section{References}

1. Digital 2020: Saudi Arabia. DataReportal. 2020 Feb 12. URL: https://datareportal.com/reports/digital-2020-saudi-arabia [accessed 2020-09-26]

2. Meier CA, Fitzgerald MC, Smith JM. eHealth: extending, enhancing, and evolving health care. Annu Rev Biomed Eng 2013;15:359-382. [doi: 10.1146/annurev-bioeng-071812-152350] [Medline: 23683088]

3. DeLuca JM, Enmark R. E-health: the changing model of healthcare. Front Health Serv Manage 2000;17(1):3-15. [Medline: 11184427]

4. Gerber T, Olazabal V, Brown K, Pablos-Mendez A. An agenda for action on global e-health. Health Aff (Millwood) 2010 Feb;29(2):233-236. [doi: 10.1377/hlthaff.2009.0934] [Medline: 20348066]

5. Global strategy on digital health. World Health Organization eHealth. 2019. URL: https://www.who.int/ehealth/en/ [accessed 2020-07-01]

6. Berwick D, Snair M, Nishtar S. Crossing the Global Health Care Quality Chasm: A Key Component of Universal Health Coverage. JAMA 2018 Oct 02;320(13):1317-1318. [doi: 10.1001/jama.2018.13696] [Medline: $\underline{\text { 30177995] }}$ 
7. Hoque R, Sorwar G. Understanding factors influencing the adoption of mHealth by the elderly: An extension of the UTAUT model. Int J Med Inform 2017 May;101:75-84. [doi: 10.1016/j.ijmedinf.2017.02.002] [Medline: 28347450]

8. Abd-Alrazaq AA, Bewick BM, Farragher T, Gardner P. Factors that affect the use of electronic personal health records among patients: A systematic review. Int J Med Inform 2019 Jun;126:164-175. [doi: 10.1016/j.ijmedinf.2019.03.014] [Medline: $\underline{\text { 31029258] }}$

9. Zhao JY, Song B, Anand E, Schwartz D, Panesar M, Jackson GP, et al. Barriers, Facilitators, and Solutions to Optimal Patient Portal and Personal Health Record Use: A Systematic Review of the Literature. AMIA Annu Symp Proc 2017;2017:1913-1922 [FREE Full text] [Medline: 29854263]

10. Institute of Medicine (US) Committee on Quality of Health Care in America. Crossing the Quality Chasm: A New Health System for the 21st Century. Washington, DC: National Academies Press; 2001.

11. Detmer D, Bloomrosen M, Raymond B, Tang P. Integrated personal health records: transformative tools for consumer-centric care. BMC Med Inform Decis Mak 2008 Oct 06;8:45 [FREE Full text] [doi: 10.1186/1472-6947-8-45] [Medline: 18837999]

12. Toscos T, Daley C, Heral L, Doshi R, Chen Y, Eckert G, et al. Impact of electronic personal health record use on engagement and intermediate health outcomes among cardiac patients: a quasi-experimental study. J Am Med Inform Assoc 2016 Jan;23(1):119-128. [doi: 10.1093/jamia/ocv164] [Medline: 26912538]

13. Heath S. How do patient portals and personal health records differ? Internet. Patient Engagement HIT. 2017 Feb 17. URL: https://patientengagementhit.com/features/how-do-patient-portals-and-personal-health-records-differ [accessed 2020-07-03]

14. Coughlin SS, Williams LB, Hatzigeorgiou C. A systematic review of studies of web portals for patients with diabetes mellitus. Mhealth 2017 Jun 12;3:23. [doi: 10.21037/mhealth.2017.05.05] [Medline: 28736732]

15. Ammenwerth E. From eHealth to ePatient: The Role of Patient Portals in Fostering Patient Empowerment. Eur J Biomed Inf 2018;14(2):20-23. [doi: 10.24105/ejbi.2018.14.2.4]

16. Ammenwerth E, Hoerbst A, Lannig S, Mueller G, Siebert U, Schnell-Inderst P. Effects of Adult Patient Portals on Patient Empowerment and Health-Related Outcomes: A Systematic Review. Stud Health Technol Inform 2019 Aug 21;264:1106-1110. [doi: 10.3233/SHTI190397] [Medline: $\underline{\text { 31438096] }}$

17. Kruse C, Argueta D, Lopez L, Nair A. Patient and provider attitudes toward the use of patient portals for the management of chronic disease: a systematic review. J Med Internet Res 2015 Feb 20;17(2):e40 [FREE Full text] [doi: 10.2196/jmir.3703] [Medline: 25707035]

18. Alanazi A, Anazi YA. The Challenges in Personal Health Record Adoption. J Healthc Manag 2019;64(2):104-109. [doi: 10.1097/JHM-D-17-00191] [Medline: 30845058]

19. Kruse CS, Bolton K, Freriks G. The effect of patient portals on quality outcomes and its implications to meaningful use: a systematic review. J Med Internet Res 2015 Feb 10;17(2):e44 [FREE Full text] [doi: 10.2196/jmir.3171] [Medline: 25669240]

20. Irizarry T, Shoemake J, Nilsen ML, Czaja S, Beach S, DeVito Dabbs A. Patient Portals as a Tool for Health Care Engagement: A Mixed-Method Study of Older Adults With Varying Levels of Health Literacy and Prior Patient Portal Use. J Med Internet Res 2017 Mar 30;19(3):e99 [FREE Full text] [doi: 10.2196/jmir.7099] [Medline: 28360022]

21. Wade-Vuturo AE, Mayberry LS, Osborn CY. Secure messaging and diabetes management: experiences and perspectives of patient portal users. J Am Med Inform Assoc 2013 May 01;20(3):519-525 [FREE Full text] [doi: 10.1136/amiajnl-2012-001253] [Medline: 23242764]

22. Bodenheimer T, Wagner EH, Grumbach K. Improving primary care for patients with chronic illness. JAMA 2002 Oct 09;288(14):1775-1779. [doi: 10.1001/jama.288.14.1775] [Medline: 12365965 ]

23. Nambisan P. Factors that impact Patient Web Portal Readiness (PWPR) among the underserved. Int J Med Inform 2017 Jun;102:62-70. [doi: 10.1016/j.ijmedinf.2017.03.004] [Medline: 28495349]

24. Zhong X, Park J, Liang M, Shi F, Budd P, Sprague J, et al. Characteristics of Patients Using Different Patient Portal Functions and the Impact on Primary Care Service Utilization and Appointment Adherence: Retrospective Observational Study. J Med Internet Res 2020 Feb 25;22(2):e14410 [FREE Full text] [doi: 10.2196/14410] [Medline: $\underline{32130124]}$

25. Fraccaro V, Vigo M, Balatsoukas P, Buchan IE, Peek N, van der Veer SN. Patient Portal Adoption Rates: A Systematic Literature Review and Meta-Analysis. Stud Health Technol Inform 2017;245:79-83. [Medline: 29295056]

26. Honein-AbouHaidar GN, Antoun J, Badr K, Hlais S, Nazaretian H. Users' acceptance of electronic patient portals in Lebanon. BMC Med Inform Decis Mak 2020 Feb 17;20(1):31 [FREE Full text] [doi: 10.1186/s12911-020-1047-x] [Medline: 32066425]

27. AlBar AM, Hoque MR. Patient Acceptance of e-Health Services in Saudi Arabia: An Integrative Perspective. Telemed J E Health 2019 Sep;25(9):847-852. [doi: 10.1089/tmj.2018.0107] [Medline: 30452333]

28. Vision 2030. National Transformation Program. URL: https://vision2030.gov.sa/en/programs/NTP [accessed 2020-06-15]

29. Belcher T, Vess J, Johnson E. Using Patient Portal Messaging to Improve Glycemic Control in Adult Patients with Diabetes in Saudi Arabia. HIMSS. 2019. URL: https://www.himss.org/resources/ using-patient-portal-messaging-improve-glycemic-control-adult-patients-diabetes-saudi [accessed 2020-05-07]

30. Alhammad O. Assessing outpatients' attitudes and expectations in secondary and tertiary hospitals in Riyadh, Saudi Arabia, Masters Thesis. Hamilton, Ontario, Canada: McMaster University; 2017. URL: https://macsphere.mcmaster.ca/handle/ $\underline{11375 / 21250}$ [accessed 2020-05-07] 
31. Al-Sahan A, Saddik B. Perceived challenges for adopting the Personal Health Record (PHR) at Ministry of National Guard Health Affairs (MNGHA)- Riyadh. Online J Public Health Inform 2016;8(3):e205 [FREE Full text] [doi: 10.5210/ojphi.v8i3.6845] [Medline: 28210426]

32. Al-Mifgai BF, Sharit J, Onar-Thomas A, Asfour S. Examining attitudes toward and ability to interact with an online personal health record: A case study in Saudi Arabia. Int J Healthc 2019 Aug 15;6(1):1. [doi: 10.5430/ijh.v6n1p1]

33. MNGHA Organization Profile. Ministry of National Guard-Health Affairs. 2018. URL: https://ngha.med.sa/English/ AboutNGHA/Pages/profile.aspx [accessed 2019-09-06]

34. MNGHA Care mobile app. Ministry of National Guard-Health Affairs. URL: https://ngha.med.sa/English/eServices/Pages/ MobileServices/patientportal.aspx [accessed 2020-04-05]

35. Sait S, Al-Tawil K. Impact of internet usage in Saudi Arabia: A social perspective. Int J Inf Technol Web Eng 2007;2(2):81-115. [doi: 10.4018/jitwe.2007040104]

36. Davis SE, Osborn CY, Kripalani S, Goggins KM, Jackson GP. Health Literacy, Education Levels, and Patient Portal Usage During Hospitalizations. AMIA Annu Symp Proc 2015;2015:1871-1880 [FREE Full text] [Medline: 26958286]

37. Osborn CY, Mayberry LS, Mulvaney SA, Hess R. Patient web portals to improve diabetes outcomes: a systematic review. Curr Diab Rep 2010 Dec;10(6):422-435 [FREE Full text] [doi: 10.1007/s11892-010-0151-1] [Medline: 20890688]

38. Morris NS, MacLean CD, Chew LD, Littenberg B. The Single Item Literacy Screener: evaluation of a brief instrument to identify limited reading ability. BMC Fam Pract 2006 Mar 24;7:21 [FREE Full text] [doi: 10.1186/1471-2296-7-21] [Medline: 16563164$]$

39. Al-Qahtani M, Alsaffar A, Alshammasi A, Alsanni G, Alyousef Z, Alhussaini M. Social media in healthcare: Advantages and challenges perceived by patients at a teaching hospital in eastern province, Saudi Arabia. Saudi J Health Sci 2018;7(2):116. [doi: 10.4103/sjhs.sjhs 36 18]

40. ALrukban A. The health related uses of social media among users in Saudi Arabia. Int J Med Sci Public Health 2014;3(12):1492. [doi: 10.5455/ijmsph.2014.170920141]

41. Alzahrani A, Alanzi T. Social Media Use By People With Diabetes In Saudi Arabia: A Survey About Purposes, Benefits And Risks. Diabetes Metab Syndr Obes 2019;12:2363-2372. [doi: 10.2147/DMSO.S208141] [Medline: 32009810]

42. Tavares J, Oliveira T. Electronic Health Record Patient Portal Adoption by Health Care Consumers: An Acceptance Model and Survey. J Med Internet Res 2016 Mar 02;18(3):e49 [FREE Full text] [doi: 10.2196/jmir.5069] [Medline: 26935646]

43. Tavares J, Oliveira T. Electronic Health Record Portal Adoption: a cross country analysis. BMC Med Inform Decis Mak 2017 Jul 05;17(1):97 [FREE Full text] [doi: 10.1186/s12911-017-0482-9] [Medline: 28679423]

44. Hoogenbosch B, Postma J, de Man-van Ginkel JM, Tiemessen NA, van Delden JJ, van Os-Medendorp H. Use and the Users of a Patient Portal: Cross-Sectional Study. J Med Internet Res 2018 Sep 17;20(9):e262 [FREE Full text] [doi: 10.2196/jmir.9418] [Medline: 30224334]

45. Amante DJ, Hogan TP, Pagoto SL, English TM. A systematic review of electronic portal usage among patients with diabetes. Diabetes Technol Ther 2014 Nov;16(11):784-793. [doi: 10.1089/dia.2014.0078] [Medline: 24999599]

46. Peacock S, Reddy A, Leveille S, Walker J, Payne T, Oster NV, et al. Patient portals and personal health information online: perception, access, and use by US adults. J Am Med Inform Assoc 2017 Apr 01;24(e1):e173-e177. [doi: 10.1093/jamia/ocw095] [Medline: 27413120]

47. Vreugdenhil M, Ranke S, de Man Y, Haan M, Kool R. Patient and Health Care Provider Experiences With a Recently Introduced Patient Portal in an Academic Hospital in the Netherlands: Mixed Methods Study. J Med Internet Res 2019 Aug 20;21(8):13743 [FREE Full text] [doi: 10.2196/13743] [Medline: 31432782]

48. Khaneghah P, Miguel-Cruz A, Bentley P, Liu L, Stroulia E, Ferguson-Pell M. Users' Attitudes Towards Personal Health Records: A Cross-Sectional Pilot Study. Appl Clin Inform 2016;7(2):573-586 [FREE Full text] [doi: 10.4338/ACI-2015-12-RA-0180] [Medline: 27437062]

49. Ronda MCM, Dijkhorst-Oei L, Rutten GEHM. Patients' Experiences with and Attitudes towards a Diabetes Patient Web Portal. PLoS One 2015;10(6):e0129403 [FREE Full text] [doi: 10.1371/journal.pone.0129403] [Medline: 26086272]

50. Showell C. Barriers to the use of personal health records by patients: a structured review. PeerJ 2017;5:e3268. [doi: 10.7717/peerj.3268] [Medline: 28462058]

51. Bauer A, Rue T, Munson S, Ghomi R, Keppel G, Cole A, et al. Patient-oriented health technologies: Patients' perspectives and use. J Mob Technol Med 2017 Aug;6(2):1-10 [FREE Full text] [doi: 10.7309/jmtm.6.2.1] [Medline: 28936236]

52. Taha J, Czaja SJ, Sharit J, Morrow DG. Factors affecting usage of a personal health record (PHR) to manage health. Psychol Aging 2013 Dec;28(4):1124-1139 [FREE Full text] [doi: 10.1037/a0033911] [Medline: 24364414]

53. Househ MS, Borycki EM, Rohrer WM, Kushniruk AW. Developing a framework for meaningful use of personal health records (PHRs). Health Policy Techn 2014 Dec;3(4):272-280. [doi: 10.1016/j.hlpt.2014.08.009]

54. Tsai J, Rosenheck R. Use of the internet and an online personal health record system by US veterans: comparison of Veterans Affairs mental health service users and other veterans nationally. J Am Med Inform Assoc 2012;19(6):1089-1094 [FREE Full text] [doi: 10.1136/amiajnl-2012-000971] [Medline: 22847305]

55. Krist AH, Woolf SH, Bello GA, Sabo RT, Longo DR, Kashiri P, et al. Engaging primary care patients to use a patient-centered personal health record. Ann Fam Med 2014;12(5):418-426. [doi: 10.1370/afm.1691] [Medline: 25354405] 
56. Coughlin SS, Heboyan V, Williams LB, Hatzigeorgiou C. Use of a web portal among adult clinic patients seen for type 2 diabetes mellitus. J Hosp Manag Health Policy 2018 Jan;2:1 [ FREE Full text] [doi: 10.21037/jhmhp.2017.12.04] [Medline: 29377041]

57. Sun R, Burke LE, Saul MI, Korytkowski MT, Li D, Sereika SM. Use of a Patient Portal for Engaging Patients with Type 2 Diabetes: Patterns and Prediction. Diabetes Technol Ther 2019 Oct;21(10):546-556. [doi: 10.1089/dia.2019.0074] [Medline: $\underline{31335206]}$

58. Tang PC, Overhage JM, Chan AS, Brown NL, Aghighi B, Entwistle MP, et al. Online disease management of diabetes: engaging and motivating patients online with enhanced resources-diabetes (EMPOWER-D), a randomized controlled trial. J Am Med Inform Assoc 2013 May 01;20(3):526-534 [FREE Full text] [doi: 10.1136/amiajnl-2012-001263] [Medline: 23171659]

59. Tao D, Or CK. Effects of self-management health information technology on glycaemic control for patients with diabetes: a meta-analysis of randomized controlled trials. J Telemed Telecare 2013 Apr;19(3):133-143. [doi: 10.1177/1357633X13479701] [Medline: 23563018]

60. Grant RW, Wald JS, Schnipper JL, Gandhi TK, Poon EG, Orav EJ, et al. Practice-linked online personal health records for type 2 diabetes mellitus: a randomized controlled trial. Arch Intern Med 2008 Sep 08;168(16):1776-1782 [FREE Full text] [doi: 10.1001/archinte.168.16.1776] [Medline: 18779465]

61. Grant RW, Wald JS, Poon EG, Schnipper JL, Gandhi TK, Volk LA, et al. Design and implementation of a web-based patient portal linked to an ambulatory care electronic health record: patient gateway for diabetes collaborative care. Diabetes Technol Ther 2006 Oct;8(5):576-586 [FREE Full text] [doi: 10.1089/dia.2006.8.576] [Medline: 17037972]

62. Timmins F. Nursing Research Generating and Assessing Evidence for Nursing Practice. Nurse Educ Pract 2013 Nov;13(6):e29. [doi: 10.1016/j.nepr.2013.04.001]

\author{
Abbreviations \\ EHR: electronic health record \\ KSA: Kingdom of Saudi Arabia \\ MNGHA: Ministry of National Guard Health Affairs \\ PHR: personal health record \\ SAR: Saudi Arabian Riyal
}

Edited by $G$ Eysenbach; submitted 30.07.20; peer-reviewed by N Fareed, J Pecina; comments to author 25.09.20; revised version
received 26.09.20; accepted 30.09.20; published 28.10 .20
Please cite as:
Yousef CC, Thomas A, Alenazi AO, Elgadi S, Abu Esba LC, AlAzmi A, Alhameed AF, Hattan A, Almekhloof S, AlShammary MA,
Alanezi NA, Alhamdan HS, Eldegeir M, Abulezz R, Khoshhal S, Masala CG, Ahmed O
Adoption of a Personal Health Record in the Digital Age: Cross-Sectional Study
J Med Internet Res 2020;22(10):e22913
URL: $\underline{\text { http://www.jmir.org/2020/10/e22913/ }}$
doi: $\underline{10.2196 / 22913}$
PMID: $\underline{32998854}$

(C) Consuela Cheriece Yousef, Abin Thomas, Ahmed O Alenazi, Sumaya Elgadi, Laila Carolina Abu Esba, Aeshah AlAzmi, Abrar Fahad Alhameed, Ahmed Hattan, Saleh Almekhloof, Mohammed A AlShammary, Nazzal Abdullah Alanezi, Hani Solaiman Alhamdan, Manal Eldegeir, Rayf Abulezz, Sahal Khoshhal, Clara Glynis Masala, Omaima Ahmed. Originally published in the Journal of Medical Internet Research (http://www.jmir.org), 28.10.2020. This is an open-access article distributed under the terms of the Creative Commons Attribution License (https://creativecommons.org/licenses/by/4.0/), which permits unrestricted use, distribution, and reproduction in any medium, provided the original work, first published in the Journal of Medical Internet Research, is properly cited. The complete bibliographic information, a link to the original publication on http://www.jmir.org/, as well as this copyright and license information must be included. 